\title{
DEFICIÊNCIA MÚLTIPLA E ESCOLARIZAÇÃO: PROCESSOS, POLÍTICA E DESAFIOS
}

\author{
MULTIPLE DEFICIENCY AND SCHOOLING: PROCESSES, \\ POLICY AND CHALLENGES
}

\author{
DEFICIENCIA MÚLTIPLE Y ESCOLARIZACIÓN: \\ PROCEDIMIENTOS, POLÍTICA Y DESAFÍOS
}

\author{
Isabel Matos Nunes ${ }^{\mathrm{I}}$ \\ Márcia Alessandra de Souza Fernandes ${ }^{\mathrm{I}}$
}

Resumo Este artigo apresenta intersecções entre duas pesquisas realizadas em São Mateus - norte do Estado do Espírito Santo, no que tange às políticas de Educação Especial no sistema municipal de ensino. Uma pesquisa problematiza a escolarização de alunos com múltiplas deficiências no contexto do município, enquanto a outra discute as ações do Conselho Municipal de Educação no que tange às políticas de educação especial. Ambas as pesquisas tomam como base de sustentação teórica a sociologia figuracional, fundamentada nos pressupostos de Norbert Elias. Os dados exibidos foram produzidos por meio do estudo de caso do tipo etnográfico, tendo como foco a constituição da política municipal local, via Conselho Municipal de Educação e a escolarização de alunos com diagnóstico de deficiência múltipla no município de São Mateus-ES. A análise evidencia que a prática conselhista pouco servirá aos anseios de um sistema educacional, se o seu colegiado não conciliar duas dimensões inter-relacionadas e complementares: a dimensão política e a técnico-burocrática.

Palavras-chave: Educação Especial; Interdependência; Política Educacional.

Abstract It presents intersections between two surveys carried out in São Mateus - north of the State of Espírito Santo, regarding Special Education policies in the municipal education system. A research problematizes the schooling of students with multiple disabilities in the context of the municipality, while the other problematizes the actions of the Municipal Council of Education with regard to special education policies. Both researches are based

\footnotetext{
${ }^{1}$ Universidade Federal do Espírito Santo (UFES), Vitória/ES - Brasil.
} 
on theoretical support of figurative sociology, based on the assumptions of Norbert Elias. The data presented were produced through a case study of the ethnographic type, focusing on the constitution of the local municipal policy, via the Municipal Council of Education and The schooling of students with multiple disabilities diagnosis in the municipality of São Mateus-ES. The analysis shows that the councilist practice will serve little the aspirations of an educational system if its collegiate does not reconcile two interrelated and complementary dimensions: the political dimension and the technical-bureaucratic dimension. Key-words: Special Education; Interdependence; Educational politics.

Resumen Se presentan intersecciones entre dos investigaciones realizadas en São Mateus - norte del Estado de Espírito Santo, en lo que se refiere a las políticas de Educación Especial en el sistema municipal de enseñanza. Una encuesta problematiza la escolarización de alumnos con múltiples discapacidades en el contexto del municipio, mientras que la otra problematiza las acciones del Consejo Municipal de Educación en lo que se refiere a las políticas de educación especial. Ambas investigaciones toman como base de sustentación teórica la sociología figuracional, fundamentada en los presupuestos de Norbert Elias. Los datos presentados fueron producidos por medio del estudio de caso del tipo etnográfico, teniendo como foco la constitución de la política municipal local, vía el Consejo Municipal de Educación y la escolarización de alumnos con diagnóstico de deficiencia múltiple en el municipio de São Mateus-ES. Que la práctica conspirativa poco servirá a los anhelos de un sistema educativo, si su colegio no conciliar dos dimensiones interrelacionadas y complementarias: la dimensión política y la técnico-burocrática.

Palabras clave: Educación Especial; Interdependencia; Política Educativa.

\section{INTRODUÇÃo}

Este texto faz uma interlocução entre duas pesquisas etnográficas realizadas no município de São Mateus-ES, dedicadas a investigar a política de Educação voltada para a escolarização de estudantes público da educação especial. Uma pesquisa intitulada "Política de escolarização de sujeitos com diagnóstico de deficiência múltipla: tensões e desafios" (NUNES, 2016) e a outra "Conselho Municipal de Educação: Figurações, interdependências e políticas de educação especial" (FERNANDES, 2016). A primeira, estuda as tensões e os desafios quanto à escolarização de alunos com diagnóstico de deficiência múltipla, tecendo suas análises a partir de um estudo macro sobre o processo de implementação da Política de Educação Especial, na região norte do Espírito Santo. A segunda, analisa as inter-relações estabelecidas nas figurações do Conselho Municipal de Educação de São Mateus-ES (CME/SM), na dinâmica de definição da política municipal da educação especial, procurando conhecer aspectos relacionados à história, à estrutura, ao funcionamento, à composição e à produção normativa desse órgão a partir da instituição do Sistema Municipal de Educação, em 2004. 
Considerando os limites deste texto, apresentaremos o panorama da política de educação especial a partir dos documentos da Política Nacional de Educação Especial, das Diretrizes do Estado do Espírito Santo e das Diretrizes do Município de São Mateus, no que tange à garantia do direito à escolarização de alunos com deficiência. Nesse percurso, exibiremos algumas análises sobre as ações do Conselho Municipal de Educação de São Mateus (CME/SM), órgão normatizador e de mobilização social daquele Sistema Municipal de Educação, procurando compreender o movimento da política de educação especial naquele contexto.

A abordagem teórico-metodológica adotada nos dois estudos se apoia, em primeiro lugar, na perspectiva de que o conhecimento historicamente produzido e acumulado pela humanidade precisa ser colocado em reflexão/discussão, já que evidencia, ele mesmo, contradições, rupturas, lacunas e desafios. E, em segundo lugar, na possibilidade de diálogo com diferentes áreas de conhecimento pois, de acordo com Elias (1994a, p. 110).

A tendência de cada grupo de cientistas de considerar seu próprio domínio como sacrossanto e como uma fortaleza para proteger intrusos com um fosso de convencionalismos e ideologias comuns àquela especialidade, obstrui qualquer intenção de relacionar as distintas áreas científicas mediante um marco de referência teórico comum [...].

A opção por esse caminho já anuncia a perspectiva que adotamos: a perspectiva sociológica figuracional que nos traz a vantagem de romper com a expectativa de um "conhecimento primeiro", necessariamente parcial e arbitrário. Sob esta análise, compreendemos que "[...] as ciências não se desenvolvem num vazio" (ELIAS, 1994a, p. 72), suas causas, seus efeitos e seu desenvolvimento são próprios a uma situação humana específica.

Destacamos que a opção por estudar as questões da Educação Especial à luz da Sociologia Figuracional torna-se um desafio agradável e instigante: primeiro, como se sabe, porque Norbert Elias não se dedicou a pesquisar as questões da Educação Especial ou da deficiência, especificamente. Uma de suas grandes questões de investigação sociológica, ao longo de mais de 50 anos, foi a relação entre indivíduo e sociedade. Segundo, pelo fato de que, a partir das janelas conceituais abertas pelo sociólogo alemão, percebemos movimentos, fluxos, descontinuidades e, entre extasiados e perplexos diante do novo, descobrimos que "[...] nos faltam conceitos e até palavras que [nos] permitam indicar uma aproximação adequada ao que está diante dos nossos olhos" (GONSALVES, 2004, p. 3).

Em busca dessa aproximação, de entender melhor o que está diante dos nossos olhos, discutimos, neste texto, alguns conceitos da Sociologia Figuracional que sustentaram nossa investigação. Concordamos com Gonsalves (2001, p. 95) quando nos alerta que "[...] a investigação social deve estar voltada para a melhoria da condição humana" e é sob esse pressuposto que nossos estudos se desenvolveram, sobretudo quanto às ações na formulação e implementação da política de escolarização dos alunos público-alvo da educação especial. Se a escola culturalmente é parte da vida das crianças e jovens, e instrumento importante na transmissão de conhecimentos, ao assumirmos esse compro- 
misso de investigação com a educação, estamos simultaneamente, assumindo um compromisso com a vida.

\title{
Contribuições de Norbert Elias na COMPreensão das tensões DA POLÍTICA LOCAL
}

Elias foi um dos principais precursores da chamada "Sociologia Figuracional", por meio da qual se estudam as relações humanas de forma processual (micro e macrossocial). Segundo esse autor, o sentido figuracional é usado para ilustrar redes de interdependência entre indivíduos e a distribuição de poder contida nessas relações.

A partir de Elias, compreendemos que as relações de poder que permeiam o processo de conhecimento numa sociedade em constante processo de civilização não é "[...] razoável, nem racional, como também não é irracional. É posta em movimento cegamente e mantida em movimento pela dinâmica autônoma de uma rede de relacionamentos" (1993, p. 195). Na concepção elisiana, esse processo é constituído nos movimentos da história, com seus fluxos e refluxos, marcando a passos lentos tanto as estruturas individuais quanto as sociais, num movimento contínuo, articulado e inter-relacionado.

Para esclarecer tal elaboração, o teórico da sociologia figuracional observou como os tratados de etiqueta e manuais de civilidade foram apropriados por grupos sociais, ao longo do tempo, para manutenção e controle das relações de poder, em determinada figuração. Em suas palavras:

\begin{abstract}
Há muito material que demonstra como, nesse período, os costumes, comportamento e moda da corte espraiavam-se ininterruptamente pelas classes médias altas, onde eram imitados e mais ou menos alterados de acordo com as diferentes situações sociais. Perdem assim, dessa maneira e até certo ponto, seu caráter como meio de identificação da classe alta. São, de certa forma, desvalorizados. Este fato obriga os que estão acima a se esmerarem em mais refinamentos e aprimoramento da conduta. E é desse mecanismo o desenvolvimento de costumes de corte, sua difusão para baixo, sua leve deformação social, sua desvalorização como sinais de distinção - que o movimento constante nos padrões de comportamento na classe alta recebe em parte sua movimentação. O importante é que nessa mudança, nas invenções e modas do comportamento da corte, que à primeira vista talvez pareçam caóticas e acidentais, com o passar do tempo emergem certas direções ou linhas de desenvolvimento. Elas incluem, por exemplo, o que pode ser descrito como o avanço do patamar do embaraço e da vergonha sob a forma de "refinamento" ou como "civilização". Um dinamismo social específico desencadeia outro de natureza psicológica, que manifesta suas próprias lealdades (ELIAS, 2011, p. 106).
\end{abstract}

A partir do movimento já descrito, fica evidente o papel que as cortes exerciam/exercem no modo das demais classes, ao imprimirem, sobretudo, mudanças e costumes quanto ao estilo de vida do indivíduo e de seus grupos. "Na lentidão dos séculos" (SARAT, 2014), 
esse processo de assimilação adentra as individualidades, moldando comportamentos de acordo com o considerado como adequado na corte.

Ciente dos limites da linguagem, Elias demonstra que, para entendermos a problemática sociológica, é preciso um trabalho de reorientação da compreensão do termo sociedade. Temos que diluir a ideia de que a sociedade é composta por estruturas que nos são exteriores - pelas quais os indivíduos estão "rodeados" - e avançar para o conceito de teias de interdependências ou configurações que, nos limitem, nos encaminhem para uma visão mais realista das disposições e afetos das pessoas em suas variadas maneiras de viver e estar no mundo.

Elias (2001, p. 92) descarta a ideia de que os fenômenos sociais possam ser compartimentalizados em "escaninhos conceituais", como políticos, econômicos, sociais, artísticos e outros, sem a devida verificação da viabilidade e adequação desses conceitos. Para ele, tal classificação "[...] certamente se relaciona com as diferenciações profissionais das sociedades nacionais industrializadas [...]" (ELIAS, 2001, p. 93) e, ao ser tomada como um padrão para outros aspectos da vida social, sem considerar seus patamares de diferenciação, dificulta a compreensão de seus fenômenos.

O autor salienta que, numa análise sociológica, o que se deve buscar é o nexo estruturado entre os indivíduos e os seus atos, em que os homens singulares não perdem o seu valor pela sua condição de singular, nem devem ser tratados como indivíduos isolados, independentes dos demais, muito menos vistos como sistemas fechados, contendo o esclarecimento final acerca de determinado evento histórico. Em suas palavras:

\footnotetext{
$\mathrm{Na}$ análise das figurações, os indivíduos singulares são apresentados de maneira como podem ser observados: como sistemas próprios, abertos, orientados para a reciprocidade, ligados por interdependências dos mais diversos tipos e que formam entre si figurações especificas, em virtude de suas interdependências. Mesmo os grandes homens, no sentido de juízo de valor de ordem especificamente sociológica, mesmo os mais poderosos têm sua posição como membros nessa cadeia de interdependências (ELIAS, 2001, p. 51, grifos do autor).
}

Desse modo, as ações dos indivíduos desenvolvem-se numa relação de interdependência a partir de uma esfera de atuação específica, ou seja, as ações dos indivíduos se dão de maneira articulada às de outros indivíduos, numa dependência recíproca. Indivíduo e sociedade estão em estreita conexão, resultando de uma cadeia de acontecimentos, também eles resultantes das inter-relações estabelecidas.

Assim, compreendemos que interdependência, na concepção elisiana, se refere às redes de dependência que constituem a moldura das decisões e o caráter de atuação dos indivíduos. Elias elabora que,

[...] como em um jogo de xadrez, cada ação decidida de maneira relativamente independente por um indivíduo representa um movimento no tabuleiro social, jogada que por sua vez acarreta um movimento de outro indivíduo - ou, na realidade, de muitos outros indivíduos -, limitando a autonomia do primeiro e demonstrando sua dependência (ELIAS, 2001, p. 158). 
Destarte, a ação relativamente independente de um jogador coloca em questão a ação de outro ou outros, e a multiplicidade de indivíduos interdependentes evidencia que as figurações são específicas, uma vez que constituídas na dinâmica das formulações históricas. Para o autor, a noção de liberdade absoluta do indivíduo, sem vínculo com outros indivíduos, é mera especulação, que facilmente se dissolveria, se deixássemos de lado explorações filosóficas e metafísicas e buscássemos fatos observáveis e verificáveis. Nessa busca, descobriríamos "[...] diversos graus da independência e de dependência entre os indivíduos, ou seja, diversos graus de poder em suas relações recíprocas” (ELIAS, 2001, p. 158).

Sobre essa perspectiva, procuramos analisar a política de educação especial, tomando-a como uma figuração específica, mas também buscando compreender as interdependências entre os fatos históricos que vão estabelecendo uma dinâmica própria, fazendo pender a balança de poder dessa figuração. E, para vislumbrar tal movimento, utilizaremos as lentes de Elias, no caso, as lentes elisianas.

\section{A educaÇão especial no Espírito Santo}

Conhecer os primórdios da Educação Especial no Espírito Santo nos possibilita entender as tensões políticas e econômicas e as relações de força (ELIAS, 2006) que impulsionaram as concepções e a política atual de Educação Especial assumidas por esse Estado. Nessa direção, apontamos como objetivo neste subitem, a problematização da história da Educação Especial no Espírito Santo.

Nosso fio condutor, a partir daqui, será o trabalho de Fernanda Ferreyro Monticelli, que investiga os "Processos de Exclusão da/na escola no Estado do Espírito Santo na Primeira República (1889-1930)", defendido em 2014, no Programa de Pós-Graduação em Educação da UFES. Utilizaremos também as Diretrizes Estaduais de Educação Especial no Espírito Santo, publicadas no ano de 2011.

Na ponta do fio, as primeiras experiências educacionais no Espírito Santo remontam à chegada dos jesuítas, sobretudo à chegada do Padre José de Anchieta, que além de dominar perfeitamente o espanhol, sua língua nativa, aprendeu o português quando radicado em Coimbra e estudou no Colégio dos Jesuítas. Destacou-se em latim e aprendeu a língua tupi, a fim de catequizar os indígenas (SAVIANI, 2010).

Entre suas muitas atividades, como diretor da Companhia de Jesus, Anchieta visitava aldeias, fazendas e engenhos. Foi por essa época que estreitou seus contatos no Espírito Santo. Chegando ao Estado, destacou-se entre os jesuítas que ancoraram no Estado e se colocou como “[...] agente da civilização pela palavra” (MONTICELLI, 2014, p. 52).

A autora assinala que no Espírito Santo, como resultado de um processo educacional excludente observado igualmente em todo país, um número considerável de crianças não chegava a ingressar na escola ou, quando iniciavam os estudos, ficavam pelo caminho. Outro dado mencionado por Monticelli (2014) é que a realidade da falta de saúde, somada à pobreza, perpetuou-se no Estado, de modo que a anormalidade também foi associada à doenças e à pobreza. A autora observa que [...] todos os que não eram considerados saudáveis 
eram taxados de inabilitados, anormais, pois representavam riscos às pessoas, que viviam sob a subjetivação do discurso higienista. A saúde estava na simetria, na padronização, na disciplina (MONTICELLI, 2014, p. 59).

Os estudos de Araújo (2011), Câmara (2011) e Monticelli (2014) mostram que nas últimas décadas do século XIX e nos primeiros anos do século XX, no Brasil, a exemplo dos "países civilizados", interessava aos médicos higienistas imprimir uma política de controle sobre a população pobre da cidade, vista como propagadora de doenças e de surtos. Tal política consistia em penetrar na esfera privada da vida dos pobres, e se utilizava da educação higiênica como estratégia de formação de hábitos morais. Câmara (2011) ressalta que, no Brasil, a intervenção era no sentido de validar a educação higiênica e a puericultura como conhecimentos a serem incorporados às escolas públicas, escolas normais e Faculdades de Medicina, além de disseminar esse conhecimento junto às mães, principalmente, as de classe popular.-

Monticelli (2014) apresenta como essa política de educação higienista foi incorporada à educação no Espírito Santo. De acordo com a autora,

[...] o Art. 23, do Capítulo III referente às aulas e seus regimes, da Lei no. 545, do ano de 1909 prescrevia que, para a primeira matrícula nas escolas primárias, fosse necessária a certidão ou documento que provasse ter a [...] creança a idade mínima de 7 annos, bem como attestado médico, que prove não soffrer de molestia contagiosa e certificado de vaccinação com resultado favorável [...] (ESPÍRITO SANTO, 1909c, p. 43, apud MONTICELLI, 2014).

O fragmento do documento nos aponta adesão à vertente médico-pedagógica que, a partir da primeira metade do século XX, sobretudo com o desenvolvimento da psicologia infantil, por meio dos estudos de Itard, Binet, Piaget e seguidores, ganhou impulso. Decorrente desse processo, foram criadas no Brasil organizações de caráter privado e filantrópico que prestavam atendimento às pessoas com deficiência.

Nas terras capixabas, as instituições filantrópicas especializadas em Educação Especial foram criadas a partir da década de 50, do século XX (ESPÍRITO SANTO, 2011).

Embora o estudo de Monticelli (2014) tenha sido realizado com minucioso olhar sobre as fontes históricas, a partir de análise dos arquivos públicos do Estado, não há indícios no seu texto de atendimento a pessoas com deficiência múltipla, ou com graves comprometimentos. A ausência aqui nos remete ao silenciamento desses sujeitos na história da Educação Especial, no Espírito Santo.

Como ação da Política Educacional no Estado, o atendimento na área da Educação Especial tem início em 1957, “[...] com a criação da classe especial para atendimento a alunos que apresentavam deficiência auditiva, no Parque Infantil Ernestina Pessoa, ${ }^{1}$ dando origem, mais tarde, em 1960, à Escola Especial Oral e Auditiva"2 (ESPÍRITO SANTO,

\footnotetext{
Atualmente a Escola Estadual de Educação Especial "Oral e Auditiva" trabalha com o enfoque bilíngue, tendo sido transformada no Centro de Atendimento ao Surdo (CAS).

2 Escola municipalizada, atualmente, localizada em Maruípe-Vitória/ ES.
} 
2011, p. 11). Além desse marco histórico, outros fatos que marcaram a Educação Especial no Espírito Santo, foram:

Em 1964, foi criada a primeira classe especial para deficientes mentais, no Grupo Escolar Suzete Cuendet. Ainda na mesma década, foi implantado o Programa de Atendimento ao Deficiente Visual, na Biblioteca Pública Estadual e, em 1970, foi criado o Serviço de Educação de Excepcionais na Diretoria do Ensino Fundamental. Por meio do Decreto n. ${ }^{\circ}$ 917/76, criou-se o Setor de Educação Especial, inserido no Departamento de Educação Supletiva. Em 1980, foi realizado o I Encontro Estadual de Educação Especial e, em 1983, foi implantado na SEDU o Serviço de Avaliação e Triagem de alunos para classes especiais, constituído por uma equipe multidisciplinar (pedagogo, psicólogo, fonoaudiólogo e assistente social (ESPÍRITO SANTO, 2011, p. 11).

A presença dos profissionais das áreas da psicologia e fonoaudiologia no serviço de avaliação e triagem de alunos para classes especiais, criado na década de 80 , no governo do Estado, configura a marca da vertente médico-pedagógica, observada nas primeiras décadas do Século XX, no Brasil, como também a marca da assistência social, configurando o lugar da Educação Especial como serviço da assistência e da caridade. Sobre esse aspecto, há de se destacar que, em um país marcado pela pobreza, além da falta de prioridade com as pessoas, como é o caso do nosso, as questões relativas à deficiência também foram atravessadas pela escassez de recursos e de serviços especializados.

Jannuzzi (1992) considera que a vertente médico-pedagógica, observada nos anos 80, era subordinada ao médico, não só na determinação do diagnóstico, mas também no âmbito das práticas escolares. No entanto, cabe destacar que, para o período em questão, o papel dos profissionais da saúde e da assistência social foi de extrema importância para o desenvolvimento da Educação Especial no Espírito Santo.

É no fluxo do trabalho dos profissionais da saúde, da reabilitação e da assistência social que, na década de 60, o Movimento Apaeano expandiu-se e adentrou o Estado. De início, a Sede da Associação de Pais e Amigos dos Excepcionais (APAE) funcionava no Instituto Educacional do Espírito Santo (INEDES), que prestava atendimento a crianças excepcionais, tendo sido fundado em 7 de maio de 1965 e atendia a 50 crianças na época. ${ }^{3}$

Na década de 80, com o movimento de discussão pela redemocratização e institucionalização das demandas educativas que antecederam a elaboração da Carta Constituinte, a Educação Especial ganha novos contornos e é contemplada no texto da Constituição Federal (BRASIL 1988), cujo artigo 208 define que o “[...] dever do Estado com a Educação será efetivado mediante a garantia de: III - atendimento educacional especializado aos portadores de deficiência, preferencialmente na rede regular de ensino".

Naquele ano, a Secretaria de Educação do Estado do Espírito Santo dá um salto para que a Educação Especial saia dos contornos e entre para a Política Educacional: a Educação Especial passa a compor o Departamento de Apoio Técnico e Pedagógico (DAT) da

3 http://www.apaees.org.br/artigo.phtml/4112 
Secretaria. Tal ação demandou outra necessidade: formação de professores especializados. Nesse mesmo ano, foi realizado o $1^{\circ}$. Curso de Especialização da Educação Especial, em convênio com a Universidade Federal do Espírito Santo (ESPÍRITO SANTO, 2011).

A partir da década de 1990, o Estado amplia o movimento da universalização da educação, à luz dos indicativos contidos em um amplo debate internacional, inspirado por organismos internacionais e caracterizados pelo discurso da educação para todos, pela focalização de investimentos no ensino fundamental e pela descentralização de ações, recursos e responsabilidades. No Brasil, tais condições marcaram reformas estruturais na educação.

$\mathrm{O}$ advento de conferências internacionais, convenções e similares em âmbito internacional impulsionou avanços políticos, culturais e filosóficos. No entanto, o ponto crucial para a elaboração das políticas de inclusão educacional foi a Conferência Mundial sobre Necessidades Educacionais Especiais: acesso e qualidade (1994), promovida pelo governo espanhol e a Organização das Nações Unidas para a Educação, a Ciência e a Cultura (UNESCO), com a participação de delegados de 87 países, de onde derivou a conhecida Declaração de Salamanca (1994), utilizada como referência internacional basilar na área da Educação Especial (PLETSCH, 2011).

Seguindo o fluxo da década de 90 , entendemos que o trabalho de elaboração das políticas educacionais é atravessado por tensões, embates e negociações entre agências internacionais de interesses locais diferenciados. Nesse embate, a atuação do Estado está comprometida com uma agenda internacional, que visa, entre outras metas, ao estabelecimento de uma "educação para todos", conforme propõe a Declaração de Salamanca. Em letras:

\footnotetext{
[...] crianças e jovens com necessidades educacionais especiais devem ter acesso às escolas regulares, que a eles devem se adequar [...], [já que tais escolas] constituem os meios mais capazes para combater as atitudes discriminatórias [...], construindo uma sociedade inclusiva e atingindo a Educação para Todos [...] (UNESCO, 1994, p. 8-9).
}

Os apontamentos advindos das orientações dos documentos internacionais e do Ministério da Educação marcaram a reorganização e reestruturação dos sistemas de ensino como eixo central, que se prolongariam no processo de aprendizagem na classe comum. No Estado do Espírito Santo, entre as ações realizadas nesse período, destaca-se "[...] a criação das salas de apoio destinadas ao atendimento dos alunos com dificuldades de aprendizagem e alunos com deficiência mental, as quais, posteriormente, passaram a ser designadas como salas de recursos" (ESPÍRITO SANTO, 2011).

Imbuída das ideias disseminadas na Declaração de Salamanca, que orientava a educação para todos os alunos, sem qualquer tipo de discriminação, e das determinações advindas da Política Nacional de Educação Especial (BRASIL, 1994), na década de 90, a Equipe de Educação Especial da Secretaria Estadual de Educação (SEDU), visando à promoção da inclusão, no ensino regular, de todos os alunos com necessidades educacionais especiais, inicia um trabalho mais intenso de extinção das classes especiais e ampliação do atendi- 
mento em salas de recursos e o atendimento itinerante (ESPÍRITO SANTO, 2011), o qual já vinha acontecendo em outros Estados do país.

Em 1994, é publicada a Política Nacional de Educação Especial, orientando o processo de "integração instrucional" que condiciona o acesso às classes comuns do ensino regular àqueles que “(...) possuem condições de acompanhar e desenvolver as atividades curriculares programadas do ensino comum, no mesmo ritmo que os estudantes ditos normais" (p. 19).

Observamos, nas ações do Estado, a força reguladora da educação e do trabalho nas escolas públicas. O Estado do Espírito Santo absorveu as políticas internacionais mais amplas, coerentes com as formulações neoliberais e gerencialistas, fortemente dominadas pela esfera econômica. Uma possível interpretação é que as implicações dessas mudanças políticas são balizadoras da organização das escolas e da garantia da escolarização dos alunos público-alvo da Educação Especial no Espírito Santo.

Padilha e Oliveira (2013), ao discorrerem sobre "Estado, direito e inclusão Escolar", ajudam-nos nessa reflexão sobre o papel que o Estado vem assumindo dentro do contexto das políticas neoliberais:

[...] apesar de o discurso de órgãos internacionais de financiamento defender uma concepção de Estado mínimo e descentralizador, seu papel tem sido crucial na definição e na implementação de políticas educacionais em consonância com o que estabelecem essas agências de financiamento, sobretudo para os países periféricos (PADILHA; OLIVEIRA, 2013, p. 32).

O papel regulador do Estado, em consonância com o conjunto de reformas políticas produzidas pelo governo federal e com as agências de financiamento, vem, na área educacional, efetivando alterações profundas na configuração da educação. Hypólito (2007) afirma que as políticas recentes preconizam um Estado forte, que exerce controle centralizado sobre aspectos fundamentais, como:

[...] a definição de currículo nacional; programas de formação docente articulados com a Mídia (principalmente eletrônica) - programas de educação a distância, pacotes pedagógicos e aquisição de equipamentos para viabilizar o acesso dos grandes grupos de comunicação às escolas, o que é muito articulado com o mercado de computadores e outras tecnologias; controle sobre livros didáticos; e assim por diante (HYPOLITO, 2007, p. 12).

Sob essa compreensão, o trabalho docente ganha centralidade na política neoliberal que regula a profissionalização e reforça processos de desqualificações profissionalizantes (HYPOLITO, 2007). De fato, presenciamos, nos últimos anos, uma proliferação de formações a distância, e mesmo presenciais, voltadas para a educação inclusiva. Tais formações têm como objetivo principal a "educação para todos", projeto do governo federal emanado das políticas de financiamento das agências internacionais. 
Dentro desse processo, sob a perspectiva de "educação para todos", a SEDU, já na década de 90, iniciou algumas formações, em áreas específicas da Educação Especial, para os professores da educação básica. A partir de 1995, além dos cursos já oferecidos para as áreas específicas, essa secretaria, em parceria com o MEC, promoveu o curso "Necessidades Especiais em Sala de Aula", com o objetivo de formar professores da educação comum, na perspectiva da inclusão escolar. Concomitantemente a essas ações, foi criada a primeira sala de recursos para alunos com altas habilidades/superdotação, em 1995, no Projeto de Atendimento ao Aluno Talentoso (PAAT). Três anos depois, em 1998, também foi inaugurado o Centro de Apoio Pedagógico para Atendimento às Pessoas com Deficiência Visual (CAP). No ano de 2003, ocorreu a implantação da primeira classe hospitalar na cidade de Vitória (ESPÍRITO SANTO, 2011).

No documento das Diretrizes Estaduais de Educação Especial no Espírito Santo foi justificada a construção das políticas de inclusão do aluno com deficiência na escola comum, em consonância com a Declaração de Salamanca e com as Diretrizes Nacionais para Educação Especial na Educação Básica (MEC/SEESP, 2001). Essas diretrizes explicitam que os sistemas de ensino devem adotar uma nova postura, propondo no projeto político-pedagógico, no currículo, na metodologia, na avaliação e nas estratégias de ensino, ações que favoreçam a inclusão social e as práticas educativas diferenciadas.

Conforme vimos, no fluxo das tensões políticas, o discurso internacional aderido pelo governo federal vai se ramificando e presentificando nas práticas dos Estados, que têm um papel fundamental na regulação e no controle das políticas educacionais. Assim como "[...] o jogador de cartas é dependente de seu jogo e do destino de seus parceiros" (ELIAS, 2001a, p. 153), no jogo político, as ações do Estado incidem a respeito dos modos de subjetivação em uma sociedade, pois constituem eixos orientadores no processo educacional. Nessa rede, o Estado é interdependente do mercado e das agências internacionais. Ao legislar ou informar, os enunciados políticos regulamentam a vida social, produzem efeitos, sentidos de verdade ou falsidade, de correto ou errado, de justo ou injusto, de melhor ou pior - efeitos de sentido sobre práticas educacionais, que se dizem inclusivas.

Ainda sobre a política de educação especial, vale ressaltar que, no percurso histórico ao qual nos propusemos a seguir, não encontramos, nos trabalhos estudados, referências às ações políticas específicas para as crianças com deficiência múltipla e/ou com comprometimentos mais severos. A ausência de ações específicas para esse público, dentro de um contexto que vem disseminando um paradigma de educação para todos, nos leva a inferir que, por trás da ausência, nos discursos, está o descrédito em relação à educabilidade e à escolaridade desses sujeitos.

Ainda que mantendo o mesmo contexto do território do Espírito Santo, adentraremos, a seguir, no contexto de um sistema específico, auxiliados pelas lentes elisianas, a fim de analisar as inter-relações estabelecidas nas figurações do Conselho Municipal de Educação de São Mateus-ES (CME/SM), na dinâmica de definição da política municipal da educação especial. 


\section{O Conselho Municipal de EducaÇão e a Constituição da Política de EducaÇão Especial no Sistema de São Mateus}

Segundo Gonçalves (2010), a história da educação especial na Rede Municipal de São Mateus dá seus primeiros passos, quando em 2001, 32 estudantes com deficiência começaram a ser atendidos, a partir de suas especificidades, numa sala de recursos de uma escola da rede. Ainda que desprovida de estrutura, orientações e recursos, a iniciativa deu visibilidade à demanda dos estudantes da educação especial, há muito posta. Como a rede municipal não tivesse experiência com a demanda que então se apresentava com força e muitas carências, nasceu, em 2005, o Núcleo de Educação Inclusiva Municipal (NEIM), que, mesmo sem regulamentação, funcionou até 2008.

Naquele período, São Mateus foi administrado pelo mesmo prefeito, em mandatos consecutivos (2001/2004 e 2005/2008), e a Secretaria Municipal de Educação esteve sob o comando da mesma secretária. $\mathrm{O}$ ano de 2009, além dos novos representantes no Executivo e na secretaria de educação também trouxe mudanças para a educação especial: o fechamento do NEIM e a aposta no AEE nas salas de recursos.

A Tabela 1 mostra o movimento das matrículas da educação especial na educação infantil e no ensino fundamental, a partir de 2008.

Tabela 1 - Matrículas da Educação Especial na Educação Infantil e no Ensino Fundamental em São Mateus

\begin{tabular}{l|c|c|c|c|c|c}
\hline \multirow{2}{*}{ Ano } & \multirow{2}{*}{$\begin{array}{l}\text { População } \\
\text { Estimada }\end{array}$} & \multirow{2}{*}{$\begin{array}{c}\text { Total Geral } \\
\text { de matrícula }\end{array}$} & \multicolumn{4}{|c}{$\begin{array}{c}\text { Matrícula de Educação Especial por } \\
\text { Dependência Administrativa }\end{array}$} \\
\cline { 4 - 7 } & & & Estadual & Municipal & Privada & Total \\
\hline 2008 & 100.655 & 26.448 & 81 & 201 & 198 & 480 \\
\hline 2009 & 101.613 & 26.256 & 34 & 110 & 213 & 357 \\
\hline 2010 & 109.028 & 26.094 & 57 & 178 & 16 & 251 \\
\hline 2011 & 110.454 & 25.929 & 123 & 240 & 16 & 379 \\
\hline 2012 & 111.832 & 25.858 & 101 & 271 & 16 & 388 \\
\hline 2013 & 120.725 & 25.597 & 130 & 259 & 28 & 417 \\
\hline 2014 & 122.668 & 25.305 & 112 & 272 & 22 & 406 \\
\hline
\end{tabular}

Fonte: Instituto Brasileiro de Geografia e Estatística (2014); Instituto Nacional de Estudos e Pesquisas Educacionais Anísio Teixeira (2014)

De início, chamamos a atenção para o aumento da população e a queda de matrícula no quadro geral: de 2008 a 2014. Embora a população continuasse crescendo, temos uma queda no quadro geral de 1.143 matrículas.

A respeito da educação especial, situação semelhante: o ano de 2008 foi o ano da publicação da Política Nacional de Educação Especial na perspectiva da inclusão escolar (BRASIL, 2008) e também do ápice das matrículas na modalidade. Interessante que, mes-

4 Nota: Dados adaptados por Fernandes (2016). 
mo com o crescimento da população em mais de $20 \%$, de 2008 a 2014, não foram tantas as matrículas na modalidade como naquele ano. A dinâmica do fluxo das matrículas nesses sete anos é extremamente intensa. O ano de 2009, marcado pela aprovação das Diretrizes Operacionais para o Atendimento Educacional Especializado - Resolução n ${ }^{\circ} .4$ (BRASIL, 2009), e o primeiro do novo governo, apresenta grande queda de matrícula, exceto nas escolas privadas, que mostram crescimento em relação às outras dependências administrativas tanto naquele ano como no anterior. Nos anos seguintes, no entanto, essas mesmas redes têm drástica redução nos seus matriculados.

Em 2014, conforme os dados já apresentados, das $406^{5}$ matrículas da educação especial, contabilizadas na educação infantil e no ensino fundamental no território mateense, 272 estão na Rede Municipal, o que corresponde a mais de $66 \%$ do total.

Em 2015, ano em que iniciamos o nosso levantamento de dados, a oferta dos serviços da modalidade na rede, com 296 estudantes matriculados, deu-se a partir de 17 salas de recursos multifuncionais, ainda que apenas 14 estivessem em pleno funcionamento, dentro de um universo de mais de 110 escolas, acontecendo em escolas-polo. Na lista de serviços ofertados, havia o de cuidador, com 52 pessoas contratadas e nenhum auxiliar de educação especial, embora a política municipal recomendasse os serviços desse profissional para atuar na sala de aula comum, com o professor regente, a fim de fazer a intervenção pedagógica nos casos de deficiência intelectual.

\section{EduCAÇÃo ESPECIAL NA PAUTA dAS discuSSÕes}

A fim de compreender o percurso da educação especial no CME de São Mateus, com suas idas e vindas tanto na pauta do colegiado quanto no cenário do sistema municipal, evocamos as discussões elaboradas por Pantaleão, Sobrinho e Sá (2014), ao analisarem o contexto e a dinâmica de aprovação do atual Plano Nacional de Educação (PNE), com foco na Meta 4.

Os três autores, ao analisarem a processualidade das inter-relações humanas sob a ótica da sociologia figuracional, elaborada por Elias, especialmente com base nas reflexões sobre o modelo de jogo, concebem que todo o percurso do Plano, da elaboração à aprovação, assumiu uma complexa configuração em que o equilíbrio de poder apresentou-se, conforme a perspectiva elisiana, naturalmente variável e instável. Segundo eles, a partir de Marchi Júnior (2003), a processualidade analisada sob a perspectiva do jogo

[...] pode nos ajudar a compreender melhor os mecanismos de concorrência social mais complexos ou invisíveis nas sociedades recentes. Afinal, na perspectiva de Norbert Elias, assim como na sociedade, no jogo, os jogadores estão em um movimento contínuo orientado por níveis de interdependência, multipolaridade de tensões e relações de poder (PANTALEÃO; SOBRINHO; SÁ, 2014, p. 2, grifo dos autores).

\footnotetext{
5 Apresentamos os números de 2014, porque ainda não estão disponíveis os de 2015.
} 
Sobre esse viés, supera-se a tendência em se relacionarem opções de causa e efeito, poder e submissão, como se essas relações fossem estáticas, possibilitando, a partir da interdependência entre os indivíduos e seus grupos, enxergar distintas e complexas formas de organização da vida social, em cuja paisagem fervilham relações dinâmicas e sempre instáveis de poder.

Os três autores destacam que desse processo podem emergir consequências que ninguém planejou, visto que o jogo se dá num movimento sem direção por causa da influência e das jogadas de cada jogador. A "[...] interdependência, como característica peculiar da condição humana, evidencia a impossibilidade de um indivíduo determinar o processamento do jogo, no qual, necessariamente, participam outros indivíduos [...]" (PANTALEÃO; SOBRINHO; SÁ, 2014, p. 3). Ela se dá no entrecruzamento de jogadas durante uma partida que, além de ir mudando o próprio jogo, também constitui as pistas que encaminham a novas jogadas.

Sob tais reflexões, tomamos a trajetória, aqui apresentada, da política de educação especial via CME/SM como um jogo, cuja configuração, constituída de jogadores em inter-relações dinâmicas e complexas, "[...] mobilizados por uma diversidade de interesses que se cruzavam e que se interpenetravam permanentemente [...]" (PANTALEÃO; SOBRINHO; SÁ, 2014, p. 7) - seja com o Poder Público, com o segmento por ele representado, com o Sindicato, com o chefe, com o estudante-filho, seja com o estudante-comunidade, entre outros - está constantemente a tensionar o equilíbrio de poder, mantendo-o variável e instável.

De maneira geral, a análise dos documentos desse jogo aponta quatro momentos ou partidas em que essa modalidade foi tema de trabalhos no CME/SM.

O primeiro momento aconteceu no período de elaboração da Resolução $\mathrm{CME} / \mathrm{SM}$ n. ${ }^{\circ}$ 04/2008. No momento em que o país vivia a implementação da Política Nacional de Educação Especial na Perspectiva da Educação Inclusiva, o CME/SM publicou a resolução da educação especial com algumas aproximações.

O segundo momento em que a modalidade esteve na pauta do Colegiado deu-se quando a Secretaria Municipal de Educação, em 2008, decidiu pelo fechamento do NEIM, que funcionava desde 2006, como já referido. Na ocasião, o CME formou comissão para discutir o assunto, na intenção de demover os gestores da decisão, mas sem sucesso.

O episódio do fechamento do Núcleo provoca algumas reflexões sobre a relevância de se instituírem políticas de Estado e não políticas de governo, que têm o caráter da transitoriedade, cuja duração, quando muito, coincide com a duração dos próprios governos (BORDIGNON, 2009).

No caso, já que não há outros registros no CME sobre o Núcleo, pelo que conseguimos resgatar nas entrevistas, ele surgiu da necessidade de um espaço específico para a educação especial, onde a Rede Municipal pudesse oferecer algum serviço aos estudantes e aos profissionais da modalidade, formação e apoio.

A respeito da necessidade de políticas educacionais na perspectiva inclusiva, com vistas a preservar o direito de todos à educação, Prieto (2001) salienta que há uma série 
de fatores implicados que vão além do espaço da sala de aula ou de outros espaços isoladamente, e "[...] que depende[m] de um conjunto articulado de mudanças que devem ser sustentadas pelo poder público [...]", tais como adoção de diretrizes legais, concepção de inclusão, organização e funcionamento do sistema de ensino, gestão do sistema de ensino, financiamento da educação e condições de trabalho do professor. Do conjunto, chamamos atenção para as diretrizes legais, referidas pela autora, que, no caso do NEIM, foi o que faltou, além da falta de vontade política.

O terceiro momento da educação especial no CME/SM aconteceu quando a Secretaria Municipal de Educação solicitou revisão da Resolução n. ${ }^{\circ}$ 4/2008, destacando a necessidade de adequação, por parte do SME/SM, à política nacional.

Os trabalhos realizados resultaram na Resolução n. ${ }^{\circ} 11 / 2012$, que trouxe a necessidade de criação de cargos na estrutura da administração municipal, como a regulamentação de outros que já existiam na prática desde 2009, como intérprete, profissional de apoio, cuidador, ${ }^{6}$ professor bilíngue e professor de braille. Embora o documento tenha sido homologado pelo secretário de educação, não logrou força de norma, porque não foi publicado.

A partir de 2013, uma série de eventos incidiram negativamente sobre os serviços ofertados aos estudantes da modalidade, e aqueles que não tinham regulamentação foram suspensos. Um grupo de pais acionou a Justiça e esta recomendou que o Executivo encaminhasse à Câmara de Vereadores projeto de lei para regulamentar os cargos e estabelecer as normatizações necessárias.

Tais recomendações levaram a educação especial para o CME outra vez, quando este elaborou a Resolução 12/2014, configurando-se assim o quarto momento da modalidade no colegiado. Como esse processo só foi concluído em outubro, as escolas encerraram aquele ano letivo contando apenas com parte dos serviços necessários aos estudantes da modalidade. A expectativa era que, no ano seguinte, todos os serviços fossem normalizados, o que não aconteceu.

Durante as entrevistas, os conselheiros afirmavam que a esse respeito algo precisava ser feito pelo CME, mas não sabiam dizer o quê, como se eles não fossem membros do Colegiado, indiferentes à questão de que a situação precisava ser encabeçada por algum conselheiro, podendo ser ele mesmo.

Das recomendações do Ministério Público, apenas a Resolução foi transformada em lei. Ainda assim, os cargos nela previstos precisavam ser regulamentados em legislação específica, o que não aconteceu, exceção para o cargo de cuidador, que já consta em legislação. Assim, como os demais cargos não estão previstos em legislação municipal, não houve abertura de vagas no concurso público que ocorreu no segundo semestre de 2015, depois de mais de oito anos sem esse tipo de seleção para o quadro de servidores efetivos da municipalidade local. O edital contemplou diversas áreas, entretanto, das demandas da educação especial, apenas o cargo de cuidador foi contemplado, com oito vagas.

E, assim, o jogo continua.

6 Único profissional regulamentado na Lei n. ${ }^{\circ} 073$, de 3 dezembro de 2013, que dispõe sobre o plano de cargos e carreiras do quadro técnico-administrativo municipal.

Comunicações $\mid$ Piracicaba $\mid$ v. $25 \mid$ n. $1 \mid$ p. 217-238| janeiro-abril 2018231 
Os encaminhamentos dados evidenciam apenas a dimensão normativa do Colegiado. Embora os conselheiros entrevistados reconheçam a necessidade de o CME assumir uma postura em relação à negação do direito dos estudantes da educação especial, o órgão tem-se limitado aos aspectos burocráticos de sua atuação, seja na elaboração da normativa, transformando-a em lei municipal, seja na discussão com autoridades.

Durante o nosso tempo em campo, a educação especial não esteve em qualquer ponto de pauta das plenárias realizadas, apesar de a maioria dos conselheiros provir de escolas, e de nenhuma dessas instituições ter todos os serviços conforme determinados pela Resolução n. $^{\circ} 12 / 2014$. Além do próprio aspecto da pesquisa em andamento e das questões trazidas durante as conversas sobre o estudo, não identificamos qualquer discussão que evidenciasse que o órgão estaria tomando alguma medida, de modo a acionar, por exemplo, sua função mobilizadora.

Esses limites na atuação do CME nos convidam a observar suas inter-relações com a Secretaria Municipal de Educação. Pelo que conseguimos apurar, existe uma preocupação muito grande por parte do Colegiado quanto à legitimidade de suas ações. Nas reuniões, há sempre um conselheiro perguntando acerca dos limites do Conselho, sobre como ele deve ou não deve fazer. O Colegiado está muito preso aos aspectos burocráticos de sua atuação, perseguindo os trâmites técnicos; por sua vez, a Secretaria não parece considerar tais aspectos quando decide adotar alguma ação.

Com relação às lentes elisianas, temos a compreensão de que essa figuração não seja determinada a priori; ela vem constituindo-se no fluxo histórico, num terreno "[...] ambíguo, marcado por harmonia, disputas, acordos, desacordos, enfim, um território de lutas marcado por processos de produção e reprodução social de distribuição de poder" (SOBRINHO, 2009, p. 190).

Nesse universo interdependente e dinâmico, em que situações vão acontecendo e se desdobrando em outras e outras, analisar o $\mathrm{CME} / \mathrm{SM}$ a partir de sua atuação no que concerne à garantia de escolarização dos estudantes da educação especial nos provoca a pensar sobre a atuação desse mesmo Colegiado em relação a suas outras funções, na garantia de escolarização de todos os sujeitos, já que o "[...] Conselho é apenas um acordador de quem dorme [...]", conforme o descreveu o conselheiro João Pedro.

Tomada por essas reflexões, mas ciente de que temos que considerar as margens de nosso estudo, caminhamos para a última parte do texto, onde colocamos em evidência aspectos trazidos à discussão que consideramos de relevância para outras reflexões que ele possa desencadear.

\section{CONSIDERAÇões FINAIS}

Durante o nosso percurso sobre a história da Educação Especial no âmbito capixaba, percebemos o silenciamento institucional no que tange aos alunos com diagnóstico de deficiência múltipla. Aliás, como falar em escolarização de um público historicamente considerado "não educável"? Ao analisar o silêncio, percebemos que os alunos com deficiência 
foram constituídos, no fluxo da história, como um grupo de "menor valor", estigmatizado pela "anormalidade" e pelos serviços segregados às margens da sociedade.

Puxando os fios, no fluxo das tensões políticas, visualizamos que o discurso internacional aderido pelo governo federal se ramificou e se presentificou nas práticas dos Estados. Conforme nos mostram os trabalhos de Mendes (2006), Kassar (1999, 2000), Jannuzzi (2004), entre outros, as agências internacionais têm um papel fundamental na regulação e no controle das políticas educacionais no Brasil.

De acordo com Elias (2001a, p. 53), “[...] o jogador de cartas é dependente de seu jogo e do destino de seus parceiros". No jogo político, as ações do Estado incidem sobre os modos de subjetivação em uma sociedade, pois constituem eixos orientadores no processo educacional. Cria-se, assim, uma rede de interdependências, em que o Estado é dependente do mercado e das Agências Internacionais. Ao legislar ou informar, os enunciados políticos regulamentam a vida social, produzem efeitos, sentidos de verdade ou falsidade, de certo ou errado, de justo ou injusto, de melhor ou pior - efeitos de sentido sobre as práticas educacionais que se dizem inclusivas.

Assim, nesse universo interdependente e dinâmico, em que situações vão se desdobrando em outras e outras, analisar as políticas de educação especial nos provoca a pensar sobre a ação dos organismos internacionais que com suas conferências, convenções e similares vão impulsionando transformações e conformações nas políticas locais. Por sua vez, também somos tomados a pensar como os colegiados vão assumindo e ratificando tais orientações, compreendendo que esses espaços, como o analisado, ocupam lugar e condição ambivalentes, pois se constituem em espaços legítimos de mudanças muito significativas, podendo assumir centralidade em muitas decisões políticas, ao mesmo tempo em que se apresentam como possibilidade de superação de modelos hierarquizados e centralizados no campo das políticas educacionais.

Nossa assertiva baseia-se tanto na literatura recorrente sobre CME (SAVIANI, 1999; CURY, 2005; SARMENTO, 2005; BORDIGNON, 2009), quanto no que evidenciam variados estudos acadêmicos que, de modo geral, confirmam os CME como espaços de grande potencial político, mas que também revelam entraves comuns a serem enfrentados para que eles se constituam em verdadeiras instituições da participação democrática.

Variados estudos enfatizam que a participação encontra muitos entraves presentes não só nos espaços dos conselhos, mas além deles, referindo-se à herança de um país fortemente marcado pela pouca tradição com os componentes republicanos de nossa democracia. Tais entraves reforçam a construção de uma relação Estado/Sociedade baseada no autoritarismo, na carência e no privilégio de alguns, mediada pela tutela e favor e, mais recentemente, pelo populismo e clientelismo (MARTINIANO, 2010; MOURA, 2010; ALVES, 2011; NATAL, 2011; OLIVEIRA, 2011; BASÍLIO 2012; PEREIRA, 2013; SOUZA, 2013).

Com as lentes de Elias, visualizamos os CMEs como espaços de figurações específicas, cujas relações interdependentes compõem uma balança que, dependendo da figuração estabelecida, pode pender para um lado ou para outro. Entretanto, ao considerar os aspectos já relacionados e a minguada tradição no que diz respeito aos aspectos republicanos e de- 
mocráticos de nossa história, invariavelmente, essa figuração tem determinado o lado para o qual pende a balança.

Diante de quadro tão desfavorável, e ao que parece, generalizado às práticas democráticas, os conselhos são cotidianamente bombardeados por ações que tentam minar o seu papel. Ainda assim, os mesmos estudos evidenciam que esses espaços possuem potencialidades como arenas de conflitos e negociação que, em sua amplitude, ainda precisam ser alcançadas, isto é, que o poder precisa ser mais tensionado, dada a sua condição instável.

Desse modo, ao utilizarmos as lentes elisianas para analisar o CME/SM, visualizamo-lo como um membro das figurações históricas que, a partir das suas inter-relações, vão imprimindo na história da política educacional os acontecimentos que resultam da "[...] dinâmica do entrelaçamento, com seus numerosos altos e baixos, representando a continuação, no mesmo rumo, de movimentos e contramovimentos de mudanças antigas" (ELIAS, 1993, p. 263).

Para pensarmos eventos sociais a partir de Elias, precisamos compreender a indissociabilidade entre sociedade e indivíduo, observando as relações estabelecidas entre seus indivíduos, posto que não são homogêneas, tampouco retilíneas. Sob essa concepção, percebemos as relações sociais marcadas por tensões e disputas, num jogo constante e inacabado. Assim, os elementos que visualizamos ao longo do estudo evidenciam como a política educacional, ou a falta dela, resulta da dinâmica de um imbricado jogo de relações entre conselheiros, seus segmentos e as diversas instituições que compõem o SME de São Mateus.

Sob tais orientações, entendemos que os colegiados devem ocupar-se da mobilização dos indivíduos e dos grupos, com vistas a subsidiar a constituição de políticas educacionais e a implementação de serviços e de espaços públicos que atendam tanto às demandas de escolarização, considerando o tripé acesso, participação e aprendizagem de todos, quanto a demanda relacionada à instituição de práticas democráticas na gestão dos serviços públicos.

A esse respeito, Drummond filosofa ao declarar que "[...] as leis não bastam. Os lírios não nascem das leis [...]", provocando-nos a pensar que nossas normas ainda dependem de diversos mecanismos de mobilização e controle social, dada a nossa curta tradição com os elementos relacionados ao Estado Democrático de Direito que, segundo Cury (2005, p. 18) é aquele que "reconhece e inclui o poder popular como fonte do poder e da legitimidade e o considera como componente dos processos decisórios mais amplos de deliberação pública e de democratização do próprio Estado".

\section{REFERÊNCIAS}

ALVES, E. F. Conselhos municipais de educação em Goiás: historicidade, movimentos e possibilidades, 2011, 210s. Dissertação (Mestrado em Educação) - Programa de Pós-Graduação em Educação, Universidade Federal de Goiás, Goiânia, 2011.

BASILIO, P. de M. Desafios para a formulação de políticas de educação infantil: um estudo sobre a atuação do Conselho Municipal de Educação de Duque de Caxias, 2012, 131s. Dissertação (Mestrado em Educação) - Programa de Pós-Graduação em Educação, Universidade Federal do Rio de Janeiro, Rio de Janeiro, 2012. 
BORDIGNON, G. Gestão da educação no município: sistema, conselho e plano. São Paulo: Ed. Paulo Freire, 2009.

BRASIL. Resolução CNE/CEB, n ${ }^{\circ}$. 4, de 2 de outubro de 2009. Institui as diretrizes operacionais para o atendimento educacional especializado na educação básica, modalidade educação especial. Diário Oficial da República Federativa do Brasil, Brasília, 2009. Disponível em: <http://portal.mec.gov.br/seesp/arquivos/pdf/res2_b.pdf>. Acesso em: 31 jan. 2015.

CÂMARA, S. Infância pobre e instituições assistenciais no Brasil republicano. In: FARIA FILHO, L. M. de; ARAÚJO, V. C. de (Org.). História da educação e da assistência à infância no Brasil. Vitória: Edufes, 2011.

CURY, C. R. J. O princípio da gestão democrática na educação: gestão democrática da escola pública In: BRASIL. Ministério da Educação. Gestão democrática da educação. Brasília, 2005, p. 14-19 (Salto para o Futuro, Boletim 19).

ELIAS, N. O processo civilizador: formação do Estado e civilização. Tradução de Ruy Jungmann. Rio de Janeiro: Jorge Zahar, v. 2, 1993, 2 v.

. A sociedade dos indivíduos. Rio de Janeiro: Zahar, 1994.

. A sociedade de corte: investigação sobre a sociologia da realeza e da aristocracia de corte. Rio de Janeiro: Zahar, 2001.

. Escritos e ensaios: Estado, processo, opinião pública; In: NEIBURG, 1; WAZBORT, L. (Org.). Escritos e Ensaios: Estado, processo e opinião pública. Rio de Janeiro: Jorge Zahar Ed., 2006.

. O processo civilizador: uma história dos costumes. Tradução de Ruy Jungmann. Rio de Janeiro: Jorge Zahar, v. 1, 2011, 2 v.

ELIAS, N.; SCOTSON, J. L. Os estabelecidos e os outsiders: sociologia das relações de poder a partir de uma pequena comunidade. Rio de Janeiro: Zahar, 2000.

ESPÍRITO SANTO. Diretrizes da educação especial na educação básica e profissional para a rede estadual de ensino. Vitória: Sedu, 2011.

FERNANDES, M. A. S. de. Conselho Municipal de Educação: figurações, interdependências e políticas de educação especial, 2016, 200s. Dissertação (Mestrado em Educação) - Programa de Pós-Graduação em Educação, Universidade Federal do Espírito Santo, Vitória, 2016.

GEBARA, A. Apresentação. In: GEBARA, A.; COSTA, C. J.; SARAT, M. (Org.). Leituras de Norbert Elias: processo civilizador, educação e fronteiras. Maringá: Eduem, 2014, p. $15-17$.

GONÇALVES, A. F. S. Percursos investigativos dentro do processo de inclusão escolar no estado do Espírito Santo, 2010, 165s. Tese (Pós-Doutorado em Educação Especial) - 
Programa de Pós-Graduação em Educação Especial, Universidade Federal de São Carlos, São Carlos, 2010.

GONSALVES, E. P.; Pesquisar, participar: sensibilidades (Pós) modernas. Revista Contexto e Educação, Ijui, ano 16, n. 63, jul./set. 2001.

. Da ciência e de outros saberes: trilhas da investigação científica na pós-modernidade. Campinas/SP: Editora Alínea, 2004.

HYPÓLITO, A. M. Políticas curriculares, Estado e regulação. Cedes, Campinas, v. 31, n. 113, p. 1.337-1.354, out./dez. 2010.

INSTITUTO NACIONAL DE ESTUDOS E PESQUISAS EDUCACIONAIS ANÍSIO TEIXEIRA. Censo escolar 2014. Disponível em: $<$ http://portal.inep.gov.br/basica-censo-escolar-matricula\#topoPagina>. Acesso em: 2 mar. 2015.

JANNUZZI, G. M. A. A luta pela educação do deficiente mental no Brasil, 2. ed. Campinas: Autores Associados, 1992.

MARTINIANO, M. S. Gestão democrática na educação: a experiência de participação no Conselho Municipal de Educação de Campina Grande-PB (2009-2010), 2010, 185s. Dissertação (Mestrado em Educação) - Programa de Pós-Graduação em Educação, Universidade Federal da Paraíba, João Pessoa, 2010.

MONTICELLI; F. F. Processos de exclusão da/na escola no Estado do Espírito Santo na Primeira República (1889-1930), 2014. Tese (Doutorado em Educação) - Programa de Pós-Graduação em Educação, Universidade Federal do Espírito Santo, Vitória, 2014.

MOURA, A. S. de. Democracia, participação e controle social nos conselhos municipais de educação, 2010, 167s. Dissertação (Mestrado em Educação) - Programa de Pós-Graduação em Educação, Universidade Federal da Paraíba, João Pessoa, 2010.

NATAL, C. M. O Conselho Municipal de Vitória/ES como espaço de produção das políticas educacionais: a constituição de uma esfera pública? 2011, 163s. Dissertação (Mestrado em Educação) - Programa de Pós-Graduação em Educação, Universidade Federal do Espírito Santo, Vitória, 2011.

NUNES, I. M. Política de Escolarização de sujeitos com diagnóstico de deficiência Múltipla: Tensões e Desafios. Tese (Doutorado em Educação) - Programa de Pós-Graduação em Educação, Universidade Federal do Espírito Santo, Vitória, 2016.

OLIVEIRA, I. A. de C. O Conselho Municipal de Educação como mecanismo de instituição da gestão democrática: um estudo de caso sobre as articulações do Conselho Municipal de Educação de Maricá, 2011, 106s. (Mestrado em Processos Formativos e Desigualdades Sociais) - Faculdade de Formação de Professores de São Gonçalo, Universidade do Estado do Rio de Janeiro, São Gonçalo, 2011. 
PADILHA, A. M. L.; OLIVEIRA, I. M.Inclusão escolar, diversidade e Desigualdades Sociais. In: . (Org.) Educação para todos: as muitas faces da inclusão escolar. Campinas: Papirus Editora, 2013.

PANTALEÃO, E. A.; SOBRINHO, R. C.; SÁ, M. G. C. S. de. O plano nacional de educação no jogo do atendimento ao aluno com deficiência. In: CONGRESO INTERNACIONAL PROCESOS CIVILIZATORIOS: EL LEGADO DE NORBERT ELIAS, 15, 2014, Cidade do México. Anais... Cidade do México: UNAM, 2014, v. 1, p. 1-16.

PEREIRA, S. O Conselho Municipal de Educação como espaço de participação nas decisões educacionais e da democratização da gestão pública do município de Atibaia/ SP, 2013, 184s. Dissertação (Mestrado em Educação) - Programa de Pós-Graduação em Educação, Universidade Estadual de Campinas, Campinas, SP, 2013.

PLETSCH, M. D. A dialética da inclusão/exclusão nas políticas educacionais para pessoas com deficiências: um balanço do governo Lula (2003-2010). Revista Teias, Rio de Janeiro, v. 12, n. 24, p. 39-55, jan./abr. 2011.

PRIETO, R. G. A construção de políticas públicas de educação para todos, 2001. Disponível em: $<$ http://www.educacaoonline.pro.br/index.php>. Acesso em: 2 jan. 2016.

SARMENTO, D. C. Criação dos sistemas municipais de ensino. Educação \& Sociedade, Campinas, SP, v. 26, n. 93, p. 1.363-1.390. set./dez. 2005.

SAVIANI, D. História das ideias pedagógicas no Brasil. Campinas: Autores Associados, 2010.

. Sistemas de ensino e planos de educação: o âmbito dos municípios. Educação \& Sociedade, Campinas, SP, v. 20, n. 69, p. 119-136, dez. 1999. Disponível em: <www.scielo. br/pdfles/v20n69/a06v2069.pdf>. Acesso em: 10 jul. 2012.

SOBRINHO, R. C. A relação família e escola a partir da processualidade de um fórum de famílias de alunos com deficiência: contribuições de Norbert Elias, 2009, 202s. Tese (Doutorado em Educação) - Programa de Pós-Graduação em Educação, Universidade Federal do Espírito Santo, Vitória, 2009.

SOUZA, A. S. Estudo sobre a tomada de decisão no Conselho Municipal de Educação de Mossoró-RN (1997-2010), 2013, 168s. Dissertação (Mestrado em Educação) - Programa de Pós-Graduação em Educação, Universidade do Estado do Rio Grande do Norte, Mossoró, 2013. 


\section{Dados das aUtoras}

\section{Isabel Matos Nunes}

Doutorado em Educação pela Universidade Federal do Espírito Santo. Professora da Faculdade Vale do Cricaré, atuando nos cursos de Pedagogia e Educação Física. São Mateus/ ES - Brasil. bel mnunes@hotmail.com

\section{Márcia Alessandra de Souza Fernandes}

Mestre em Educação pela Universidade Federal do Espírito Santo. Professora na Rede Municipal de São Mateus e na Rede Estadual do Espirito Santo. São Mateus/ES - Brasil. marciaasf@bol.com.br

Submetido em: 20-8-2017

Aceito em: 17-11-2017 